\title{
PRIOR YEAR ACCOMPLISHMENTS CAN OPENER PROJECT
}

\author{
Task QE1171299
}

\author{
Principal Investigator \\ Charles H. Speer \\ Fabrication Systems Department \\ Development Division
}

September 30, 1999

\author{
Prepared by the \\ Oak Ridge Y-12 Plant \\ P. O. Box 2009 \\ managed by \\ LOCKHEED MARTIN ENERGY SYSTEMS, INC. \\ for the \\ U.S. DEPARTMENT OF ENERGY \\ under contract DE-AC05-84OR21400
}




\section{DISCLAIMER}

This report was prepared as an account of work sponsored by an agency of the United States Government. Neither the United States Government nor any agency thereof, nor any of their employees, makes any warranty, express or implied, or assumes any legal liability or responsibility for the accuracy, completeness, or usefulness of any information, apparatus, product, or process disclosed, or represents that its use would not infringe privately owned rights. Reference herein to any specific commercial product, process, or service by trade name, trademark, manufacturer, or otherwise, does not necessarily constitute or imply its endorsement, recommendation, or favoring by the United States Government or any agency thereof. The views and opinions of authors expressed herein do not necessarily state or reflect those of the United States Government or any agency thereof. 


\section{TABLE OF CONTENTS}

Introduction................................................................................................

Modification and Testing ................................................................................ 1

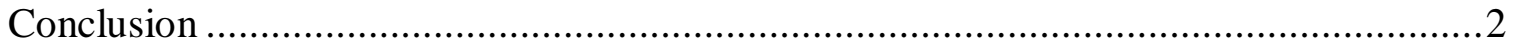

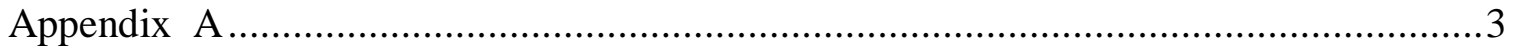

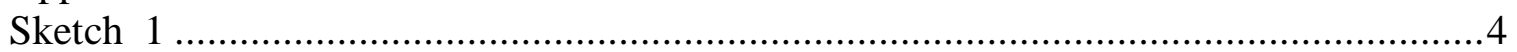

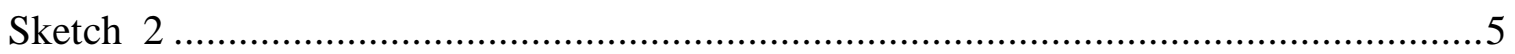

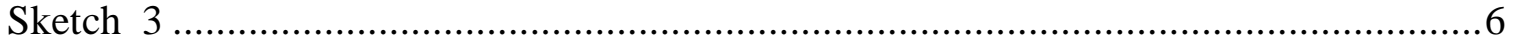




\section{INTRODUCTION}

This report documents the work preformed on the project for Quality Evaluation Organization (QEO) from October 1998 through September 1999. Welded metal cans are used to store many components in the Y-12 Plant. The current process for opening these cans is to cut off the weld with hand operated nippers or shears. This causes excessive lid destruction and it also produces a rough and uneven edge that is difficult to reweld. (See Sketch 1) QEO personnel expressed a need for a better solution to these problems. Finding a better "can opener" that is quick and easy to use, reduces lid destruction, and produces a surface that enhances rewelding was the objective of this work.

\section{MODIFICATION AND TESTING}

The evaluation can opener operation was observed and operators and supervision agreed upon a possible solution. A heavy-duty 12 gauge shear DeWALT Model DW895 was ordered. After receiving the shears it was determined that modifications should not be made to the foot cutter because this would affect the hardness of the cutter. The washer that attaches the cutter was modified to act like a guide for the cutting operation. After welding a guide on the washer a workable unit was acquired. This established an acceptable width of can lid removal. The guide had to be far enough behind the edge of the cutter to allow the cut to be started and have enough arc to allow the shears to cut the desired radius. It was speculated that the washer did not have enough weldable surface to support the guide through numerous cuts, so a washer and guide were fabricated from a solid piece of stainless steel. This was evaluated on the test samples. (See sketch 2)

The modified shears were evaluated by operations staff on production cans. It was determined that the guide needed to be moved back approximately 0.250 in. At this time, information was received that this model was no longer available and the replacement was Model DW893. These shears were lighter and easier to work with. The new shears were purchased and an evaluation was started for modifications. The foot was different so a guide was welded on the chip curler. This was then evaluated on test samples. (See Sketch 3.) It was discovered that the first shears were still being manufactured. Upon evaluating the second shears in production, it was determined that the guide was catching the cut edge of the can. The guide needed to be modified so to eliminate this problem. Operators still prefer the first model. Even though it is heavier, it seems to be more balanced. It also has a lock on switch that the second one does not have. Modifications and evaluations of both shears were continued in parallel. Both sets were modified again and checked on test samples. Both sets were taken to production for reevaluation. Model 893 needed less space under the guide, so it has been redone. Evaluation of modifications to the Model 895 shears was not completed in FY 1999. 


\section{CONCLUSION}

Both modified shears will do the intended job. Model DW895 is the choice of the operators. These shears seem to be better balanced and have a lock on switch. Model DW893 has a tendency to curl a chip with potential for housing penetration and motor stalling. 
APPENDIX A 


\section{SKETCH 1}

\section{VIEW OF CAN}

(Not to Scale)
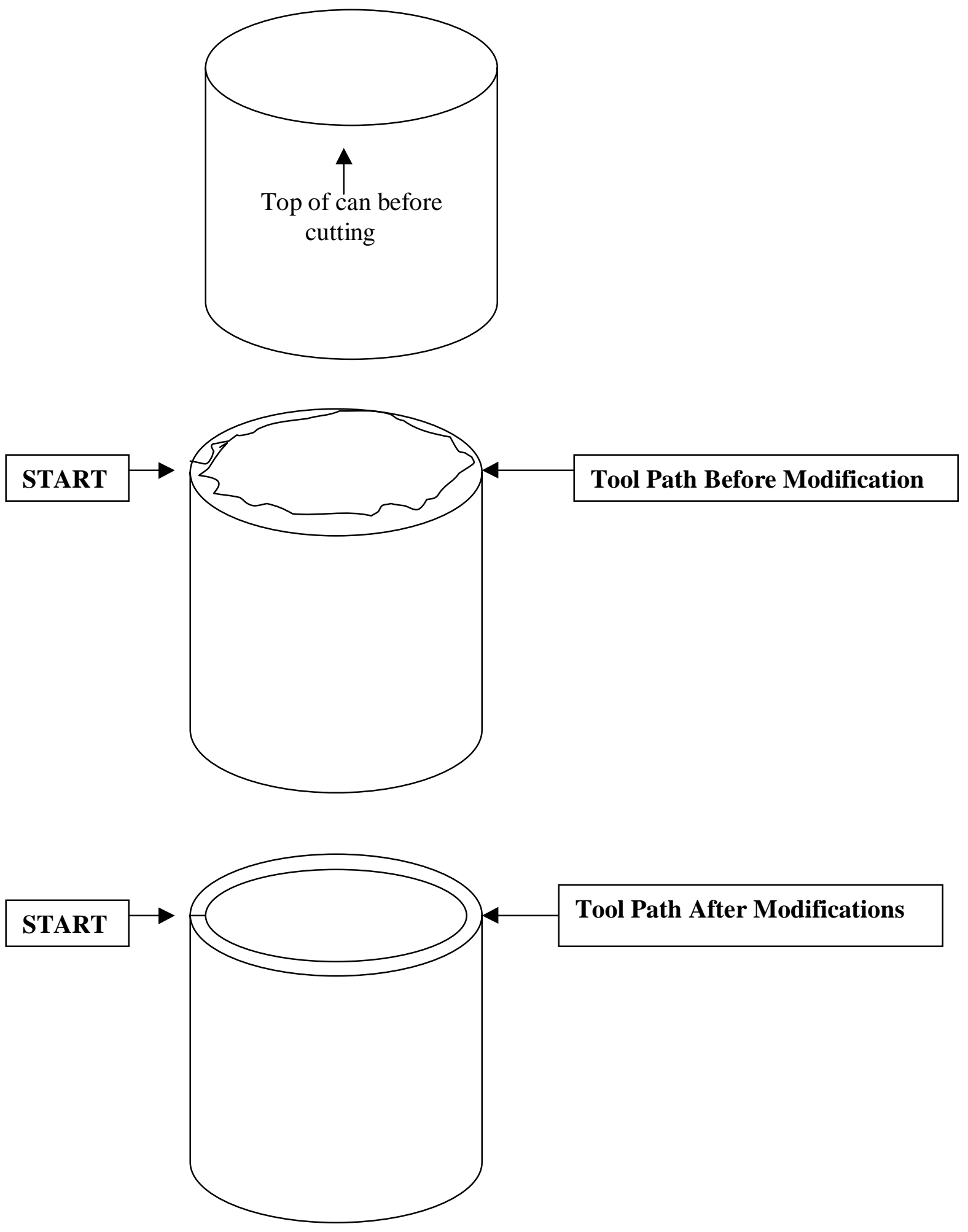


\section{SKETCH 2}

\section{FOOT AND CUTTER - DW 895}
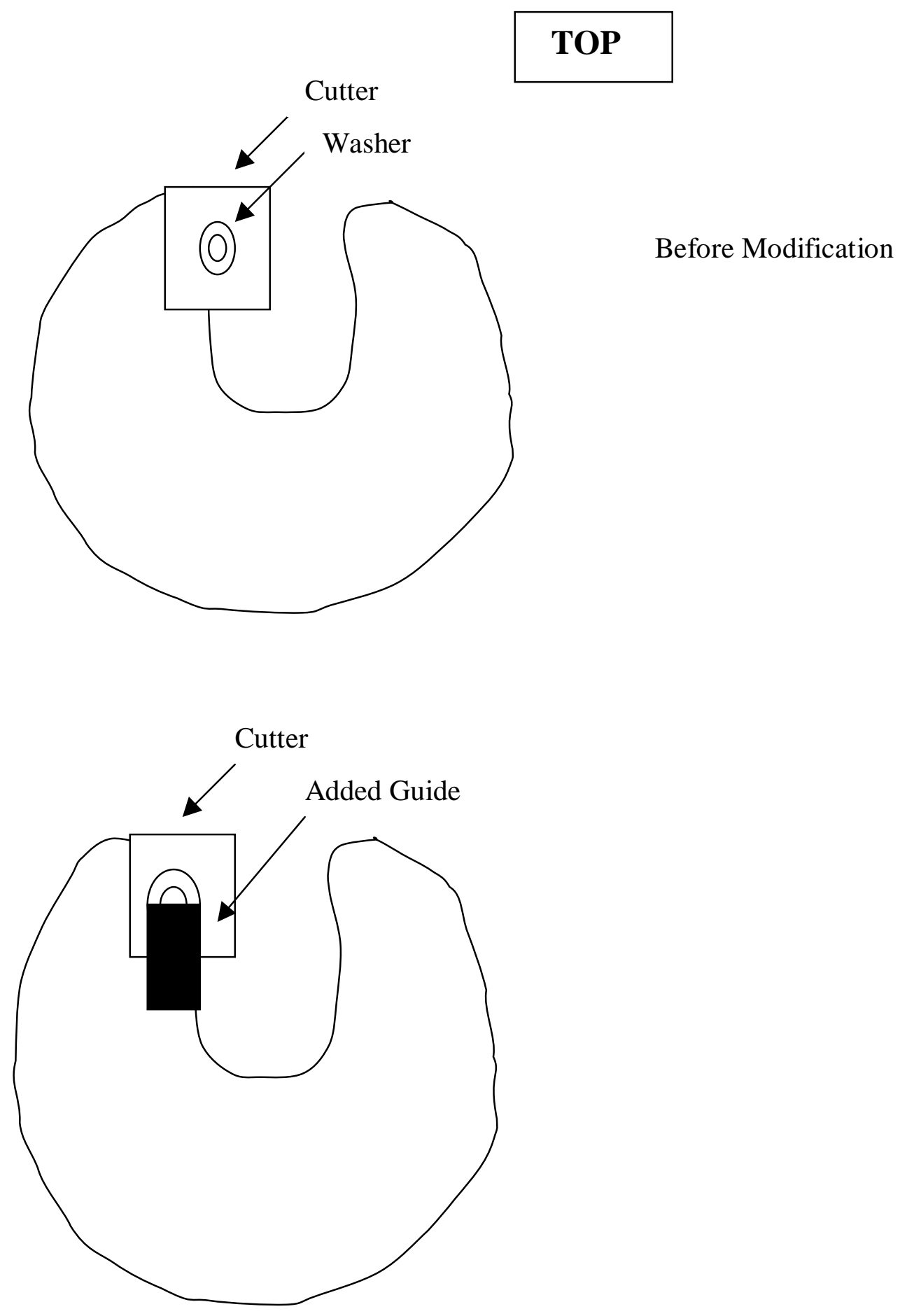


\section{SKETCH 3}

\section{FOOT AND CUTTER - DW893}
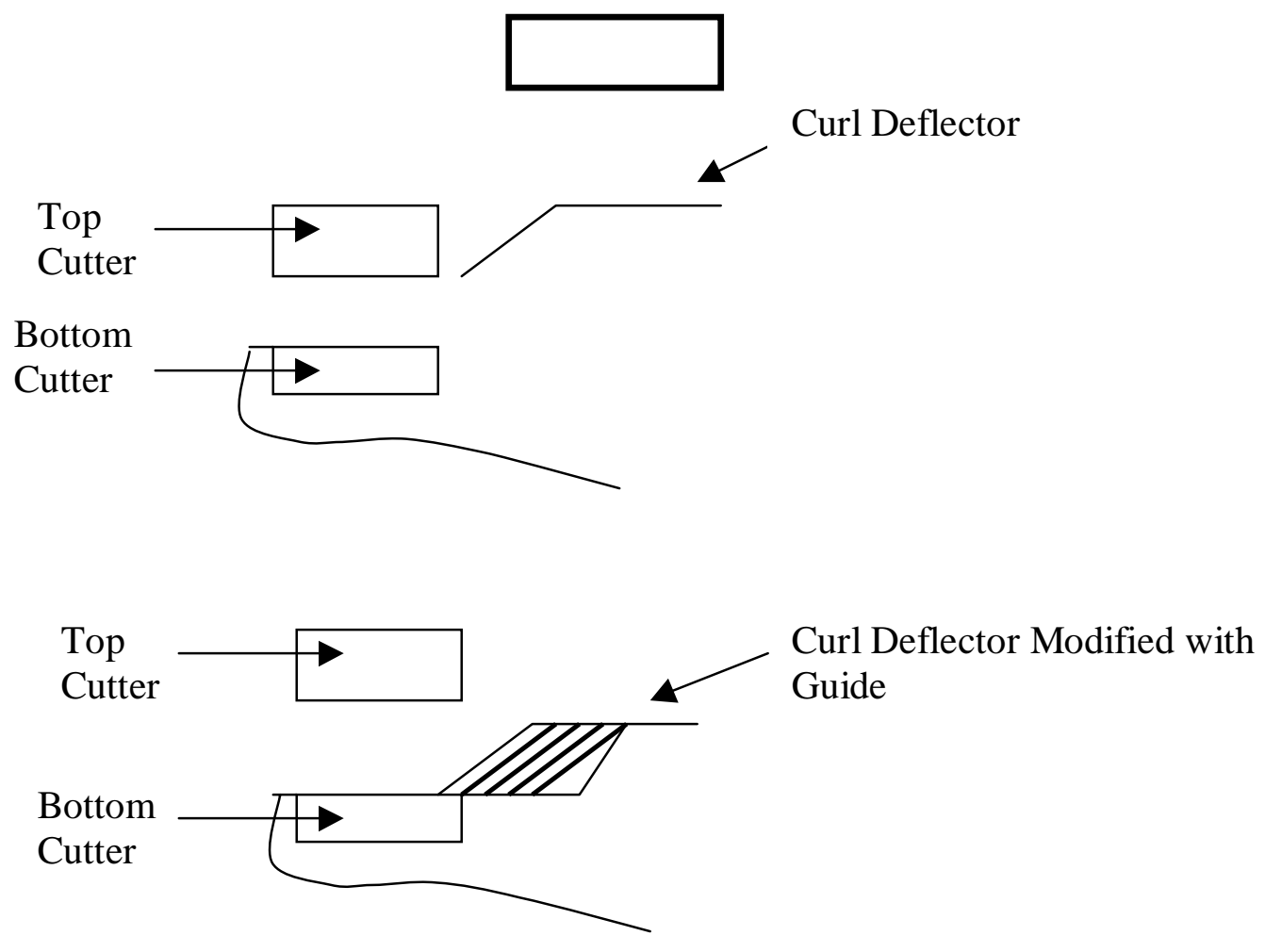

\section{FRONT}

Curl Deflector and Guide

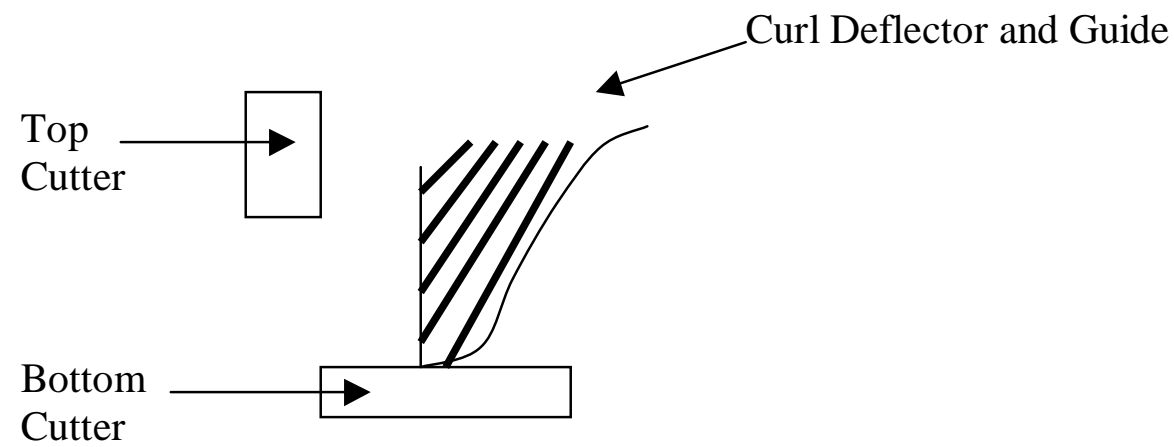




\section{DISTRIBUTION}

G. R. Brtdges

M. C. Christofferson

R. N. Hughes

D. W. Post

S. C. Robinson

C. H. Speer

Y-12 Plant Records 